\title{
DOI: http://dx.doi.org/10.33846/sfl1423
}

Efek Pendidikan Anak Usia Dini (PAUD) Bagi Kemampuan Interaksi Sosial Anak

\section{Tri Sakti Widyaningsih}

Dosen Prodi Ners, Universitas Widya Husada Semarang, Indonesia; imoet.sakti@gmail.com (koresponden) Tamrin

Dosen Prodi Ners, Universitas Widya Husada Semarang, Indonesia; ns.tamrin86@gmail.com

\begin{abstract}
Background: Given the importance of early childhood education in child growth and development, the role of child caregivers in the school area community needs to conduct research on how management provides good stimulation when children enter pre-school age by providing an overview of the effectiveness of early childhood education (PAUD) on interaction ability Children Social at RA Islamic Tunas Bangsa 4 Semarang City. Methods: This study aims to determine the effectiveness of Early Childhood Education (PAUD) on the Social Interaction Ability of Children in RA Islamic Tunas Bangsa 4 Semarang City. The type of research used was quantitative with nonexperimental used a cross-sectional design where the researcher seeks to analyze the effectiveness of children's social interaction skills assessed through the snake and ladder game intervention between groups of children who have attended PAUD and children who do not participate in PAUD in RA Islamic Tunas Bangsa 4 Semarang City by involving all children who fall into the criteria, according to the needs of the researcher. The population in this study were 57 children at kindergarten (TK A) in RA Islamic Tunas Bangsa 4 Semarang City. The sample in this study were members of the population who met the inclusion and exclusion criteria of the study sample, as many as 36 children. Results: The study used the Chi Square analysis test and statistically the p value was 0.001 (<0.05). Conclusion: The conclusion in this study is that HO is rejected Ha is accepted, there are differences in the social interaction of children who attend PAUD and do not participate in PAUD in RA Islamic Tunas Bangsa 4 Semarang City. Suggestion: So that teachers can be creative in using game tools that function to develop the social interaction skills of students in RA Islamic Tunas Bangsa 4 Semarang City.
\end{abstract}

Keywords: social interaction skills; early childhood education

ABSTRAK

Latar Belakang: Mengingat pentingnya pendidikan Usia Dini dalam pertumbuhan dan perkembangan anak, maka peran perawat anak di komunitas area sekolah perlu melakukan penelitian bagaimana cara manajemen memberikan stimulasi yang baik ketika anak memasuki usia pra sekolah dengan memberikan gambaran tentang Efektifitas Pendidikan Anak Usia Dini (PAUD) Terhadap Kemampuan Interaksi Sosial Anak Di RA Islamic Tunas Bangsa 4 Kota Semarang. Metode: Penelitian ini bertujuan mengetahui Efektifitas Pendidikan Anak Usia Dini (PAUD) Terhadap Kemampuan Interaksi Sosial Anak Di RA Islamic Tunas Bangsa 4 Kota Semarang. Jenis penelitian yang digunakan adalah kuantitatif dengan metode non eksperimental (observasional) dengan menggunakan rancangan cross sectional dimana peneliti berupaya untuk menganalisis efektifitas kemampuan interaksi sosial anak yang dinilai melalui intervensi permainan ular tangga antara kelompok anak yang sudah pernah mengikuti PAUD dan anak yang tidak mengikuti PAUD di RA Islamic Tunas Bangsa 4 Kota Semarang dengan cara melibatkan semua anak yang masuk dalam kriteria, sesuai kebutuhan peneliti. Populasi dalam penelitian ini adalah anak yang duduk pada usia taman kanak-kanak (TK A) di RA Islamic Tunas Bangsa 4 Kota Semarang sejumlah 57 anak. Sampel dalam penelitian ini adalah anggota populasi yang memenuhi kriteria inklusi dan ekslusi sampel penelitian, sebanyak 36 anak. Hasil: Penelitian menggunakan uji analisis Chi Square dan secara statistik didapatkan nilai p-value $=0,001$ $(<0,05)$. Kesimpulan :Kesimpulan dalam penelitian ini adalah $\mathrm{H}_{0}$ ditolak $\mathrm{H}_{\mathrm{a}}$ diterima, ada perbedaan interaksi sosial anak yang mengikuti PAUD dan tidak mengikut PAUD di RA Islamic Tunas Bangsa 4 Kota Semarang. Saran: Agar guru dapat berkreasi dalam menggunakan alat permainan yang berfungsi untuk mengembangkan kemampuan interaksi sosial peserta didik di RA Islamic Tunas Bangsa 4 Kota Semarang.

Kata Kunci: kemampuan interaksi sosial; pendidikan anak usia dini

\section{PENDAHULUAN}

Anak sebagai generasi penerus bangsa merupakan salah satu bagian terpenting untuk mencapai kemakmuran suatu negara, untuk itu anak-anak perlu diperhatikan dan dipantau dalam setiap tahap pertumbuhan dan perkembangannya. Perkembangan anak pada usia dini disebut sebagai masa emas "Golden Age" yang artinya bahwa perkembangan pada usia ini sangat berpengaruh terhadap perkembangan pada periode berikutnya hingga anak menjadi dewasa. ${ }^{(1)}$ Empat aspek perkembangan usia dini untuk memantau perkembangan anak adalah melalui penilaian motorik kasar, motorik halus, bahasa dan personal sosial. Perkembangan sosial merupakan suatu proses kemampuan belajar dan tingkah laku anak yang berhubungan dengan perkembangan sosial pada anak dituntut untuk memiliki kemampuan yang sesuai dengan tuntutan sosial dimana mereka berada, tuntutan sosial yang dimaksud anak dapat bersosialisasi dengan baik sesuai dengan tahap perkembangan dan usianya, serta cenderung menjadi anak yang mudah bergaul, maka dari itu perkembangan seorang anak sangat 
penting untuk diperhatikan demi terwujudnya masa depan yang baik untuk pencapaian perkembangan masa dewasa kelak. ${ }^{(2)}$

Menurut Mulyasa, anak yang mengikuti PAUD lebih baik dikarenakan mendapatkan stimulasi tambahan sesuai dengan tahapan usia anak, sehingga anak mampu bersosialisasi dengan teman sebaya, selain itu tenaga pendidikan sudah mendesain program untuk menstimulasi perkembangan anak sesuai standar pengajaran yang sudah di terapkan sehingga anak berkembang secara optimal sesuai dengan potensinya. ${ }^{(3)}$ Berdasarkan data United Nations Internatonal Children's Emergency Fund angka partisipasi pendidikan usia dini atau PAUD di Indonesia masih tergolong rendah di banding negara-negara penghasilan rendah di Asia lainnya Partisipasi PAUD di Indonesia hanya 22\%, dimana angka tersebut lebih rendah di banding Filipina sebesar 27\%, Vietnam sebesar $43 \%$, Thailand sebesar $86 \%$, dan Malaysia sebesar $89 \% .{ }^{(4)}$ Salah satu hambatan dari program PAUD yaitu kurangnya perhatian dari masyarakat terhadap program tersebut, para orangtua memilih cenderung memilih untuk langsung menyekolahkan anak-anak mereka lebih awal tanpa didahului pendidikan usia dini. Berdasarkan laporan Departemen Kesehatan Republik Indonesia cakupan pelayanan kesehatan balita dalam deteksi dini balita yang mengalami gangguan tumbuh kembang di Indonesia 43,8\%, khususnya untuk provinsi Jawa Tengah sekitar 25,3\%. Prevalansi Kemendiknas ditemukan jumlah mencapai 14 juta anak yang tidak mengikuti PAUD atau non formal. ${ }^{(5)}$

Berdasarkan hasil wawancara tanggal 13 Juli 2019 dengan kepala sekolah, di TK Tunas Bangsa 4 Kota Semarang, di dapatkan jumlah anak prasekolah sebanyak 57 anak terdiri atas 32 laki-laki dan 25 perempuan. 20 (dua puluh) anak mengikuti PAUD dan 37 (tiga puluh tujuh) anak tidak di mengikuti PAUD. Kepala sekolah juga menyampaikan anak di TK yang belum pernah sekolah di PAUD sebelumnya cenderung anaknya malu, menangis, menyendiri, interaksi kurang dan kurang dapat beradaptasi dengan sesama teman sebayanya.

Mengingat pentingnya pendidikan Usia Dini dalam pertumbuhan dan perkembangan anak, maka peran perawat anak di komunitas area sekolah perlu melakukan penelitian bagaimana cara manajemen memberikan stimulasi yang baik ketika anak memasuki usia pra sekolah dengan memberikan gambaran tentang Efektifitas Pendidikan Anak Usia Dini (PAUD) Terhadap Kemampuan Interaksi Sosial Anak Di RA Islamic Tunas Bangsa 4 Kota Semarang.

Penelitian ini bertujuan untuk mengetahui efektifitas Pendidikan Anak Usia Dini terhadap kemampuan interaksi sosial anak di RA Islamic Tunas Bangsa 4 Kota Semarang.

\section{METODE}

Penelitian ini termasuk penelitian kuantitatif dengan metode penelitian non eksperimental (observasional) dengan menggunakan rancangan cross sectional dimana peneliti berupaya untuk menganalisis efektifitas kemampuan interaksi sosial anak yang dinilai melalui intervensi permainan ular tangga antara kelompok anak yang sudah pernah mengikuti PAUD dan anak yang tidak mengikuti PAUD di RA Islamic Tunas Bangsa 4 Kota Semarang dengan cara melibatkan semua anak yang masuk dalam kriteria, sesuai kebutuhan peneliti. Populasi dalam penelitian ini adalah anak yang duduk pada usia taman kanak-kanak (TK A) di RA Islamic Tunas Bangsa 4 Kota Semarang sejumlah 57 anak. Teknik pengambilan sampel dilakukan dengan cara purposive sampling dan besar sampel minimal dihitung dengan rumus Lemeshow didapatkan jumlah sampel yaitu 36 anak yang terdiri atas 18 anak pernah mengikuti PAUD dan 18 anak tidak mengikuti PAUD di RA Islamic Tunas Bangsa 4 Kota Semarang. ${ }^{(6)}$

Kriteria Inklusi dalam pengambilan sampel ini adalah anak usia 3-6 tahun, orangtua atau guru yang setuju anaknya di jadikan peneliti (responden). Kriteria Eksklusi dalam penelitian ini adalah anak yang sedang izin, sakit ataupun tanpa keterangan pada saat penelitian berlangsung. Instrumen kemampuan interaksi sosial menggunakan lembar observasi selama dilakukan permainan ular tangga dengan berpedoman pada form Denver II. Ijasah atau raport digunakan peneliti untuk menentukan anak sudah mengikuti Pendidikan Usia Dini atau belum mengikutinya. Setelah dilakukan intervensi dan penilaian,data yang telah diperoleh diolah menggunakan analisis statistik, dimana peneliti mendeskripsikan dengan menggunakan tabel distribusi frekuensi pada analisis deskriptif dan menggunakan analisis uji Non Parametrik Mann Whitney untuk menguji dua kelompok yang berbeda. ${ }^{(7)}$

\section{HASIL}

Proses pelaksanaan penelitian dilakukan pada bulan Juli 2020 dengan judul Efektifitas Pendidikan Anak Usia Dini (PAUD) Terhadap Kemampuan Interaksi Sosial Anak DI RA Islamic Tunas Bangsa 4 Kota Semarang. Hasil penelitian yang diperoleh adalah sebagai berikut:

Tabel 1. Efektifitas Pendidikan Anak Usia Dini (PAUD) terhadap kemampuan interaksi sosial anak di RA Islamic Tunas Bangsa 4 Kota Semarang

\begin{tabular}{|c|c|c|c|c|}
\hline \multirow{3}{*}{ Pendidikan Anak Usia Dini } & \multicolumn{4}{|c|}{ Kemampuan Interaksi Sosial } \\
\hline & \multicolumn{2}{|c|}{ Baik } & \multicolumn{2}{|c|}{ Sedang } \\
\hline & Frekuensi & Persentase & Frekuensi & Persentase \\
\hline Anak Yang Mengikuti PAUD & 17 & 94,4 & 1 & 5,6 \\
\hline \multirow[t]{2}{*}{ Anak Yang Tidak Mengikuti PAUD } & 8 & 44,4 & 10 & 55,6 \\
\hline & \multicolumn{2}{|l|}{$p$-value $=0,001$} & & \\
\hline
\end{tabular}


Tabel 1 menjelaskan kemampuan interaksi sosial anak yang mengikuti PAUD di RA Islamic Tunas Bangsa 4 Kota Semarang setelah diberikan intervensi interaksi sosial (bermain ular tangga) didapatkan interaksi sosial anak dalam kategori baik dengan jumlah 17 anak $(94,4 \%)$ dan 1 anak dengan kategori sedang $(5,6 \%)$. Setelah dilakukan analisis uji Chi Square diperoleh p-value 0,001 $(<0,05)$, H0 ditolak Ha diterima dapat disimpulkan bahwa ada perbedaan efektifitas pendidikan anak usia dini terhadap kemampuan interaksi sosial anak di RA Islamic Tunas Bangsa 4 Kota Semarang.

\section{PEMBAHASAN}

Berdasarkan hasil penelitian diketahui secara umum responden pada kedua kelompok memiliki tingkat usia yang sama minimum usia empat tahun dan maksimum usia lima tahun yang mempunyai berbagai macam potensi. Potensi itu di rangsang dan di kembangkan agar pribadi anak berkembang secara optimal. Hasil observasi peneliti selama pelaksanaan penelitian, karakteristik anak prasekolah di RA Islamic Tunas Bangsa 4 Kota Semarang pada kemampuan interaksi sosial baik, anak sangat mandiri, kooperatif, mau menunggu giliran bermain ular tangga, mau minta maaf ketika salah dalam bermain, mau bekerja sama dengan temannya dan sedikit agresif. Hasil menunjukan bahwa jelas terlihat perbedaan interaksi sosialnya sama karena dari 18 anak sama-sama sudah pernah mendapatkan stimulasi terlebih dahulu di PAUD, maka ketika anak masuk ke taman kanak-kanak (TK), anak usia 4-5 tahun anak selalu diperhatikan dan dipantau dalam setiap tahap pertumbuhan dan perkembangannya, namun di RA Islamic Tunas Bangsa 4 Kota Semarang, anak yang awalnya mengikuti PAUD sudah mendapatkan bekal yang mengacu pada keterampilan, karena dapat dengan mudah berkomunikasi, mandiri dan berinteraksi dengan orang lain, adapun kegiatan yang mencakup kecerdasan untuk memimpin, berinteraksi, berbagi, menyayangi, permainan kelompok dan kerja sama, selain itu anak juga berminat dalam mengikuti program pendidikan usia dini terlebih dahulu dan orangtua mendukung kemauan anak. Beberapa hal yang perlu diketahui meningkatkan dan mempertahankan interaksi sosial anak agar anak tetap berkembang secara optimal yaitu secara rutin diterapkan stimulasi interaksi sosial kelompok baik dirumah maupun disekolah misal salah satu anak diajak dengan bermainan ular tangga, dakon dan permainan tradisional misal jamuran. Sejalan dengan penelitian yang didapatkan oleh Fristy, menyatakan bahwa permainan tradisional mampu memberikan peran positif terhadap perkembangan sosial anak yang dapat meningkatkan kemampuan anak untuk bersosialisasi, selain itu juga dapat diperhatikan komunikasi terhadap anak, lingkungan, pengawasan keluarga ataupun faktor lain yang dapat mempengaruhi perkembangan sosial terutama pada anak. ${ }^{(8)}$ Hal ini sesuai dengan teori Gerungan interaksi sosial di pengaruhi oleh faktor imitasi (peniruan), sugesti (memberi pengaruh), simpati (tertarik pada orang lain). ${ }^{(9)}$ Tujuh belas anak pada interaksi sosial baik anak mampu untuk bercengkraman dengan temannya sebelum permainan dimulai, anak mau menunggu giliran untuk bermain dan anak mau bekerjasama dengan teman sebayanya. Satu anak interaksi sosialnya sedang dikarenakan masih ada ketika salah tidak mau meminta maaf dan tidak mau untuk berbagi dengan temannya. Asumsi peneliti kemampuan berinteraksi sosial merupakan salah satu aspek karakteristik tumbuh kembang anak, dimana anak diharapkan mampu untuk berkembang sesuai tahapannya ditandai dengan salah satu yaitu kecerdasan yang dibentuk oleh anak, yakni kecerdasan interpersonal, yang menjadikan anak untuk bersosialisasi dan mandiri. Asumsi tersebut diperkuat dengan hasil penelitian sebelumnya yang dilakukan oleh Setyaningrum bahwa anak yang mengikuti pembelajaran di PAUD berpeluang mempunyai perkembangan kognitif baik hampir empat kali dibandingkan anak yang tidak ikut pembelajaran di PAUD karena pemberian stimulasi psikososial yang optimal kepada anak akan meningkatkan perkembangan kognitif anak. ${ }^{(10)}$ Sejalan dengan penelitian sebelumnya yang dilakukan oleh Wulandari tentang Perbedaan Perkembangan Anak yang Mengikuti PAUD dan tidak Mengikuti PAUD di TK ABA Suronatan Ngampilan Yogyakarta, didapatkan hasil perkembangan anak yang mengikuti PAUD Persentase anak yang tidak mengikuti PAUD dengan kategori sedang lebih besar dibandingkan Persentase interaksi sosial anak yang mengikuti PAUD. ${ }^{(11)}$ Sesuai dengan pernyataan Aisyah menjelaskan interaksi sosial yang tidak memenuhi harapan sosial dan membahayakan bagi penerimaan sosial oleh kelompok, hal ini akan menghilangkan kesempatan anak untuk belajar sosial, sehingga sosialisasi mereka semakin jauh lebih rendah dibandingkan dengan teman seusianya. ${ }^{(12)}$ Menurut peneliti, bahwa kemampuan interaksi sosial anak yang tidak mengikuti PAUD di RA Islamic Tunas Bangsa 4 Kota Semarang dipengaruhi oleh sosial ekonomi dan pola asuh orangtua. Sosial ekonomi yang cenderung akan menyebabkan orangtua tidak mengikutkan anaknya untuk sekolah PAUD karena biaya yang mahal. Interaksi sosial anak yang tidak mengikuti PAUD dengan kategori sedang karena ada dukungan faktor internal yaitu keluarga maupun lingkungan luar dan pengaruh pengalaman sosial anak maka anak mendapatkan rangsangan stimulus sehingga anak mampu untuk adaptasi dan bergaul dengan teman sebayanya, anak dengan kategori sedang selama pelaksanaan penelitian, anak bisa menyesuaikan dengan temannya, bisa menyebut nama temannya, anak mau berbagi dengan teman, bersedia menunggu giliran bermain dan bekerja sama dalam permainan ular tangga. Menurut Soerjono, kelompok sosial menilai dan menerima atas dasar kemampuan memenuhi harapan sosial, anak berusaha menyesuaikan diri secara bertahap diantaranya, teman seusia mereka lemah karena kurang mandiri, anak akan dianggap remeh oleh kelompok teman sebaya karena tampak tidak mempunyai apa-apa untuk diberikan pada kelompok, anak tidak dapat memiliki pandangan yang baik tentang diri mereka sendiri. ${ }^{(13)}$ Penelitian ini didukung oleh Sulistyawati bahwa interaksi yang terjadi dalam permainan sangat penting untuk perkembangan anak. Anak dapat mempelajari perkembangan sosial seperti kerjasama dan kolaborasi yang mendukung dan meningkatkan kognitif mereka melalui interaksi sosial dengan orang lain. Menurut hasil analisis, lingkungan yang baik akan mendukung anak untuk mencapai pertumbuhan dan perkembangan yang optimal, ketika 
masuk di TK anak sudah sedikit mampu untuk bersosial dengan teman sebayanya, anak mau diajak bermain ular tangga. Anak usia prasekolah yang telah mendapatkan motivasi oleh guru, tetap memerlukan dukungan dari orangtua untuk membangun semangat belajar, meskipun motivasi yang baik adalah motivasi yang datang dari dalam diri anak. ${ }^{(14)}$ Sesuai dengan teori Mulyasa bahwa anak yang mengikuti PAUD lebih baik dikarenakan mendapatkan stimulasi tambahan sesuai dengan tahapan usia anak, sehingga anak mampu bersosialisasi dengan teman sebaya, selain itu tenaga pendidikan sudah mendesain program untuk menstimulasi perkembangan anak sesuai standar pengajaran yang sudah diterapkan sehingga anak berkembang secara optimal sesuai dengan potensinya, sedangkan anak yang tidak mengikuti PAUD kurang maksimal dikarenakan kurangnya stimulasi dari orang tua atau keluarga, cenderung menyendiri, interaksi sosial dan adaptasi kurang. ${ }^{(3)}$ Asumsi peneliti pada anak usia pra sekolah merupakan modal awal anak untuk berkembang sesuai tahapan usia, diharapkan anak mampu dalam mengontrol diri, berinteraksi dengan orang lain, dan penggunaan bahasa dalam berinteraksi merupakan modal awal, sehingga anak dapat tumbuh dan berkembang secara optimal, dalam mempersiapkan tahap perkembangan berikutnya di tahap sekolah. Diperkuat oleh penelitian yang dilakukan Afriyanto tentang perbedaan kemampuan bersosialisasi antara anak prasekolah dengan PAUD dan tanpa PAUD, didapatkan hasil uji Mann whitney diperoleh hasil ada perbedaan kemampuan bersosialisasi anak prasekolah PAUD dan Non PAUD. ${ }^{(15)}$

\section{KESIMPULAN}

Berdasarkan hasil penelitian yang dilakukan peneliti, dapat disimpulkan ada perbedaan pendidikan anak usia dini terhadap kemampuan interaksi sosial anak.

\section{DAFTAR PUSTAKA}

1. Handayani A. Hubungan Tingkat Pengetahuan Orang Tua Tentang Stimulasi Verbal Dengan Perkembangan Bahasa Pada Anak Prasekolah di TK PGRI 116 Bangetayu Wetan. Skripsi. Semarang: Fakultas Ilmu Keperawatan dan Kesehatan Universitas Muhammadiyah Semarang; 2012.

2. Sulistiani W. Penerapan Metode Bermain untuk Meningkatkan Kemampuan Sosial Anak Usia Dini. Jurnal Ilmiah Psikologi dan Psikologi Kelautan-Kemaritiman. Surabaya: Fakultas Psikologi Universitas Hang Tuah; 2009; 3(2).

3. Mulyasa HE. Manajemen PAUD. Bandung: PT Remaja Rosdakarya; 2012.

4. UNICEF Indonesia. Pendidikan \& Perkembangan Anak Usia Dini. Jakarta: UNICEF Indonesia; 2013.

5. Kemendiknas RI. Pendidikan Anak Usia Dini. Jakarta: Kemendiknas RI; 2012.

6. Nursalam. Asuhan keperawatan bayi dan anak (untuk perawat dan bidan). Jakarta: Selemba Medika; 2013.

7. Dharma KK. Metodologi Penelitian Keperawatan: Panduan Melaksanakan dan Menerapkan Hasil Penelitian. Jakarta: Trans InfoMedia; 2011.

8. Wildaniah F. Program Bimbingan Untuk Mengembangkan Prilaku Prososial Anak Usia Dini. Skripsi. Bandung: Universitas Pendidikan Indonesia; 2013.

9. Gerungan. Psikologi Sosial. Bandung: PT Refika Aditama; 2010.

10. Setyaningrum SR, Triyanti, Indrawani YM. Pembelajaran di Pendidikan Anak Usia Dini Dengan Perkembangan Kognitif pada Anak. Jurnal Kesehatan Masyarakat Nasional; 2014; 8(6).

11. Wulandari R. Perbedaan Perkembangan Sosial Anak Usia 3-6 Tahun Dengan Pendidikan Usia Dini Dan Tanpa Pendidikan Usia Dini. Skripsi; 2016.

12. Aisyah S. Perkembangan dan Konsep Dasar Pengembangan Anak Usia Dini. Jakarta: Universitas Terbuka; 2008.

13. Soerjono. Sosiologi Suatu Pengantar. Jakarta: PT Raja Grafindo Persada; 2012.

14. Sulistyawati A. Deteksi Tumbuh Kembang Anak. Jakarta: Salemba Medika; 2014.

15. Afriyanto. Perbedaan Kemampuan Bersosialisasi dan Kematangan Emosional Antara Anak Prasekolah Dengan PAUD dan Tanpa PAUD. Skripsi; 2016. 